\title{
Biological evidence of cancer stem-like cells and recurrent disease in osteosarcoma
}

\author{
Camille Jubelin ${ }^{1,2,3}$, Javier Muñoz-Garcia², Denis Cochonneau², Emilie Moranton², Marie-Françoise \\ Heymann $^{2}$, Dominique Heymann ${ }^{1,2,4}$ \\ ${ }^{1}$ CNRS, US2B, UMR 6286, Nantes Université, Biological Sciences and Biotechnologies unit, Nantes 44000, France. \\ ${ }^{2}$ Institut de Cancérologie de l'Ouest, "Tumor Heterogeneity and Precision Medicine" Laboratory, Saint-Herblain 44805, France. \\ ${ }^{3}$ Atlantic Bone Screen, Saint-Herblain 44800, France. \\ ${ }^{4}$ Department of Oncology and Metabolism, University of Sheffield, Medical School, Sheffield S10 2RX, UK.
}

Correspondence to: Prof. Dominique Heymann, Institut de Cancérologie de l'Ouest, "Tumor Heterogeneity and Precision Medicine" Laboratory, Blvd Jacques Monod, Saint-Herblain 44805, France. E-mail: dominique.heymann@univ-nantes.fr

How to cite this article: Jubelin C, Muñoz-Garcia J, Cochonneau D, Moranton E, Heymann MF, Heymann D. Biological evidence of cancer stem-like cells and recurrent disease in osteosarcoma. Cancer Drug Resist 2022;5:184-98.

https://dx.doi.org/10.20517/cdr.2021.130

Received: 1 Dec 2021 First Decision: 13 Jan 2022 Revised: 18 Jan 2022 Accepted: 29 Jan 2022 Published: 16 Feb 2022

Academic Editors: Godefridus J. Peters, Brian A. Van Tine Copy Editor: Xi-Jun Chen Production Editor: Xi-Jun Chen

\begin{abstract}
Sarcomas are a large family of cancers originating in the mesenchyme. Composed of more than 100 histological subtypes, soft tissue and bone sarcomas remain clinically challenging, particularly in children and adolescents in whom sarcomas are the second most common malignant entities. Osteosarcoma is the main primary bone tumor in adolescents and young adults and is characterized by a high propensity to induce distant metastatic foci and become multi-drug resistant. The innate and acquired resistance of osteosarcoma can be explained by high histological heterogeneity and genetic/molecular diversity. In the last decade, the notion of cancer stem-like cells (CSCs) has emerged. This subset of cancer cells has been linked to drug resistance properties, recurrence of the disease, and therapeutic failure. Although CSCs remain controversial, many elements are in favor of them playing a role in the development of the drug resistance profile. The present review gives a brief overview of the most recent biological evidence of the presence of CSCs in osteosarcomas and their role in the drug resistance profile of these rare oncological entities. Their use as promising therapeutic targets is discussed.
\end{abstract}

Keywords: Cancer stem cells, bone sarcoma, soft tissue sarcoma, drug resistance, tumor microenvironment, recurrent disease, residual disease 


\section{INTRODUCTION}

Sarcomas are composed of highly heterogeneous soft tissue and bone oncological entities that are members of the mesenchymal tumor family ${ }^{[1,2]}$. Osteosarcoma is the main bone sarcoma, with high prevalence in adolescents and young adults. Two peaks of incidence are described in the literature, a main peak around 18 years and a second in the sixth decade of life, more frequently diagnosed in patients following Paget's disease or radiotherapy and referred to as secondary osteosarcomas ${ }^{[2-4]}$. The conventional therapeutic regimen for osteosarcoma is based on a sequential approach combining surgery and neoadjuvant and adjuvant polychemotherapies ${ }^{[5]}$. Considered to be radioresistant, radiotherapy is nevertheless part of the therapeutic arsenal, proposed in osteosarcomas for which the surgical procedure is delicate, such as tumors in high-risk locations, and can be used for better local control of the tumor ${ }^{[6]}$. Unfortunately, the therapeutic response in osteosarcoma patients has not improved in the last four decades, with an overall survival rate of around $70 \%$ after five years for localized disease. This rate drops dramatically to $30 \%$ when lung metastases can be detected ${ }^{[7]}$.

As described in other types of cancer, osteosarcoma evolves under the pressure of random mutational changes ${ }^{[8,9]}$, with preferential clonal proliferation and epigenetic modifications ${ }^{[10-13]}$ within the clonal population, leading to genetic instability, high genetic diversity, and high tumor heterogeneity ${ }^{[13,14]}$. Therapeutic failure is frequently attributed to this intratumoral heterogeneity, and more specifically to the emergence of oligoclonal tumor cells capable of evading the therapeutic drugs. From this observation the concept of CSCs has emerged, in reference to embryonic stem (ES) cells. CSCs express transcription factors (e.g., Nanog, Oct4, and Sox2) initially detected in ES cells and exhibit pluripotent differentiation properties into various functional cells able to reconstitute the complete tumor mass. The tumor-initiating cells, the CSCs, have been described as tumor cells capable of reproducing all features of the initial tumor mass and have been associated with tumor recurrence, propagation, and drug resistance ${ }^{[15-18]}$. Unfortunately, longterm relapse in patients considered clinically disease-free is observed in numerous cancers, including osteosarcoma ${ }^{[19,20]}$. Minimal residual disease is defined as malignant cells that are resistant to treatment and that remain in patients after remission, leading to relapse and metastasis. Minimal residual disease is composed of drug-resistant tumor cells and is presented dynamically as persister/dormant/quiescent/cancer cells in residual tumors, such as circulating tumor cells in peripheral blood and disseminated tumor cells in bone marrow and other metastatic sites ${ }^{[13-15,21]}$. In this context, tumor recurrence may be related to the persistence of CSCs. Increasing evidence highlights the existence of CSCs in osteosarcomas, although their real contribution to pathogenesis remains speculative. The present review aims to give a brief overview of the most recent knowledge available on CSCs in osteosarcoma and their potential clinical interest as new therapeutic targets.

\section{PROPERTIES OF CANCER STEM-LIKE CELLS IN OSTEOSARCOMA AND BIOLOGICAL IN VIVO EVIDENCE}

Around 5\% of osteosarcoma patients develop local recurrence of their disease between 6 and 28 months after their first line of treatment and disease-free survival of up to 12 years is usually observed in $46 \%$ of patients ${ }^{[22]}$. A large series confirmed a relatively low rate of local recurrence of high-grade osteosarcoma in contrast to the relapse disease associated with lung metastases ${ }^{[23,24]}$. In 2010, Perrot et al. ${ }^{[20]}$ described local recurrence with metastatic foci in patients with telangiectatic osteosarcoma of the humerus after 13 years of complete remission. The local recurrence exhibited the same histological subtype as the initial tumor and was observed at the injection site of autologous fat grafts that had been performed 18 months before the recurrence for plastic surgery. More recently, Pennati et al. ${ }^{[25]}$ studied a series of autologous fat grafts in sarcomas and did not exclude an increased risk of local recurrence after the fat grafting procedure. These clinical cases raise the question of the persistence of cancer cells that remain quiescent at the primary tumor 
site during the remission phase and are reactivated by alteration to their local microenvironment. Interestingly, in 2018, Le Nail et al. ${ }^{[26]}$ identified osteosarcoma cells with CSC properties from high-grade osteosarcoma samples. Of the isolated cells, two showed a high ability to form spheroids, and, even though they were not tumorigenic, these cells supported tumor growth when they were co-inoculated with human osteosarcoma cell lines in immunodeficient mice.

Asymmetric cell division has been described in stable cancer cell lines, leading to the development of proliferating and quiescent cells that were functionally related to sensitive and drug resistant cells, respectively ${ }^{[15]}$. The identification of CSCs in osteosarcoma has been extensively described in the literature [Table 1]. CSCs express CD24 $4^{[27]}, \mathrm{CD} 177^{[28-31]}$, Stro- $1^{[28-31]}, \mathrm{CD} 133^{[32-39]}$, and ALDH1 $1^{[39,41-43]}$ and show specific metabolic properties ${ }^{[4-47]}$. Telomerase (hTert) controls the lengthening of chromosome telomeres by catalyzing the addition of repetitive DNA sequence to their end. CD271 and Stro-1 were enriched in hTert and showed metabolic specificities such an uncoupling Warburg under hypoxia ${ }^{[31,47]}$. In addition, as expected, these cells, which expressed stemness markers (e.g., Nanog, OCT4, and Sox2), were able to form spheroids in vitro and exhibited the properties of tumor-initiating cells in preclinical mouse models ${ }^{[4]}$. Among the other metabolic particularities, CSCs exhibit high aerobic glycolysis and oxidative phosphorylation $^{[45]}$, a downregulation of the citrate cycle, and increased oxidative glutathione levels ${ }^{[46]}$ and show more generally an upregulation of most amino acid metabolisms ${ }^{[4,46]}$. A drug resistant profile has been associated with the stemness properties of CSCs, which can be modulated by epigenetic mechanisms such as DNA and mRNA methylation ${ }^{[4,49]}$ and with an increase in ALDH activity and ABC transporter expression $^{[50,51]}$. Interestingly, anti-cancer therapies based on cytotoxic agents result in enrichment of CSCs in cancer cells, highlighting the potentially harmful link between CSCs and the establishment of drug resistance ${ }^{[52-54]}$. CSCs may be a specific subset of tumor cells with high potential for tumor-initiation and self-renewal, as has been recently observed in all primary cultures from cases of patient-derived Ewing sarcoma ${ }^{[55]}$.

\section{MOLECULAR REGULATION OF CANCER STEM-LIKE CELLS IN OSTEOSARCOMA}

Osteosarcoma growth and the distant dissemination of cancer cells are controlled by a permanent dialog between cancer cells and their microenvironment ${ }^{[2,56]}$. These soluble and membranous mediators trigger specific intracellular molecular cascades that lead to control of cellular processes, including cell death, epithelial-mesenchymal transition, or spreading, but also proliferation and quiescence. In this context, the behavior of CSCs is controlled by the tumor microenvironment. In recent decades, key signaling pathways regulating CSCs have been identified and become the source of therapeutic development [Figure 1].

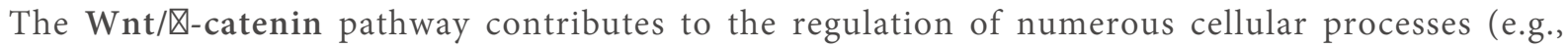
proliferation, differentiation, and polarization) and is thus strongly associated with embryonic development. The Wnt glycoprotein family is composed of 19 secreted members that interact with cell membranes after binding to 1 of the 10 Frizzled receptors identified which are G protein-coupled receptors or to a coreceptor such as LRP-5 or -6 or tyrosine kinase receptor chains including retinoic acid-related orphan receptor and RyK. In the absence of Wnt ligand, $\beta$-catenin is degraded by the proteasome after sequestration associated GSK-3 $\beta$, and the Wnt/ $\beta$-catenin pathway is considered as inactive. The Wnt $/ \beta$ catenin pathway is activated by the binding of one Wnt ligand to its receptor/co-receptor complex that leads to a series of phosphorylation cascades and recruitment of the receptor chains and then to the inactivation of the $\beta$-catenin degradation process. Consequently, $\beta$-catenin accumulates to the cytoplasm and is translocated into the nucleus before interacting with transcription factors, members of the TCF/LEF family, and activating target genes [Figure 1]. Any disturbance (e.g., mutations or activation) in this molecular pathway leads to pathological situations ${ }^{[57]}$. Recently, Deng et al ${ }^{[58]}$ studied the involvement of Indian 
Table 1. Biological characteristics and functional properties of CSCs identified in human osteosarcoma

\begin{tabular}{|c|c|c|c|}
\hline $\begin{array}{l}\text { Biomarkers } \\
\text { studied }\end{array}$ & Biological properties & Models & Ref. \\
\hline CD24 & $\begin{array}{l}\text { - Sphere formation } \\
\text { - Expression of stemness markers (Oct4, Nanog, Sox2, } \\
\text { BMI1) } \\
\text { - Properties of tumor-initiating cells } \\
\text { - Drug resistance }\end{array}$ & $\begin{array}{l}\text { - MNNG-HOS, U2OS, MG- } 63 \text {, and OSC228 } \\
\text { human cell lines } \\
\text { - Primary cultures of human cancer cells }\end{array}$ & {$[27]$} \\
\hline \multirow[t]{4}{*}{ CD117, Stro-1 } & $\begin{array}{l}\text { - Expression of stemness markers (CD133, CXCR4, } \\
\text { Nanog, Otc4) }\end{array}$ & - K7M2 mouse cell line & {$[28]$} \\
\hline & - In vivo properties of tumor-initiating cells & $\begin{array}{l}\text { - 318-1, P932, and K7M2 mouse cell lines and } \\
\text { KHOS and MNNG/HOS human cell lines }\end{array}$ & [29] \\
\hline & \multirow{2}{*}{$\begin{array}{l}\text { - Drug resistance (ABCG2): resistance to methotrexate, } \\
\text { cisplatin }\end{array}$} & - U2OS human cell line & {$[30]$} \\
\hline & & $\begin{array}{l}\text { - MG63, MNN/HOS, and 143B human cell lines } \\
\text { and patient-derived cells }\end{array}$ & [31] \\
\hline \multirow[t]{6}{*}{ CD133 } & $\begin{array}{l}\text { - Sphere formation } \\
\text { - Expression of stemness markers (Sox2, Oct3/4, Nanog) }\end{array}$ & - SaOS2, MG63, and U2OS human cell lines & {$[32]$} \\
\hline & - Expression of ABCG2 and MDR1 & $\begin{array}{l}\text { - Primary cultures of human cancer cells and } \\
\text { MG63 human cell line }\end{array}$ & [33] \\
\hline & $\begin{array}{l}\text { - Expression of } A B C B 1, A B C C 2 \text {, and the metastasis- } \\
\text { associated genes } \beta 4 \text {-integrin, ezrin, MMP-13, and CXCR4 }\end{array}$ & - FFFE samples and MG63 human cell line & {$[34]$} \\
\hline & $\begin{array}{l}\text { - Concomitant CD133/CXCR4 expression significantly } \\
\text { associated with lung metastasis }\end{array}$ & - SaOS2 human cell line & {$[35,36]$} \\
\hline & \multirow[t]{2}{*}{$\begin{array}{l}\text { - Expression of CD133 and ALDH1 positively associated } \\
\text { with lymph node metastasis and distant metastasis }\end{array}$} & $\begin{array}{l}\text { - FPPE samples and } \mathrm{SaOS} 2, \mathrm{U} 2 \mathrm{OS}, \mathrm{MG} 63 \text {, HOS, } \\
\text { MNNG/HOS, HuO9, and } 143 \mathrm{~B} \text { human cell lines }\end{array}$ & [37] \\
\hline & & - FFPE samples & {$[38,39]$} \\
\hline CD271 & $\begin{array}{l}\text { - Sphere formation } \\
\text { - Ability for self-renewal } \\
\text { - Resistance to DDP therapy } \\
\text { - Overexpression of Nanog, Oct3/4, STAT3, DNA-PKcs, } \\
\text { Bcl-2, and ABCG2 } \\
\text { - In vivo tumorigenicity }\end{array}$ & $\begin{array}{l}\text { - FFPE samples and U2OS, MNNG/HOS, and } \\
\text { SaOS2 human cell lines }\end{array}$ & {$[40]$} \\
\hline \multirow[t]{4}{*}{ ALDH1 } & $\begin{array}{l}\text { - Sphere formation } \\
\text { - Ability for self-renewal }\end{array}$ & - FPPE samples & [39] \\
\hline & $\begin{array}{l}\text { - Expression of stemness markers (CD133, CXCR4, } \\
\text { Nanog, Otc4, Sox2, KLF4) }\end{array}$ & - MG63 human cell line & [41] \\
\hline & - Drug resistance & $\begin{array}{l}\text { - HuO9, OS99-1, MG63, and SaOs2 human cell } \\
\text { lines }\end{array}$ & {$[42]$} \\
\hline & - In vivo tumorigenicity & $\begin{array}{l}\text { - HOS, MG63, MHM, MNNG/HOS, OHS, and } \\
\text { U2OS human cell lines }\end{array}$ & [43] \\
\hline hTERT enrichment & $\begin{array}{l}\text { - Expression of CD117 and Stro-1 } \\
\text { - Spheroid formation }\end{array}$ & $\begin{array}{l}\text { - Primary osteosarcoma cell lines (OS1-4) } \\
\text { - MG63, MNNG/HOS, and 143B human cell lines }\end{array}$ & [31] \\
\hline \multirow[t]{4}{*}{ Metabolic properties } & $\begin{array}{l}\text { - Specific metabolic feature of osteosarcoma stem-like } \\
\text { cells: amino acid, fatty acid, energy, and nucleic acid }\end{array}$ & - 143B and MG63 human cell lines & {$[44]$} \\
\hline & $\begin{array}{l}\text { - Involvement of the Rap1 and Ras signaling pathways in } \\
\text { methotrexate resistance }\end{array}$ & - OS13 human cell line & {$[45]$} \\
\hline & $\begin{array}{l}\text { - High aerobic glycolysis and oxidative phosphorylation: } \\
\text { association to LINB28 expression }\end{array}$ & - HOS human cell line & {$[46]$} \\
\hline & $\begin{array}{l}\text { - Downregulation of the citrate cycle and elevation of } \\
\text { oxidized glutathione levels } \\
\text { - Upregulation of most of the amino acid metabolisms } \\
\text { - Uncoupling Warburg and stemness in } \mathrm{CD}_{133^{+}} \text {cells } \\
\text { under hypoxia }\end{array}$ & - SaoS2 human cell line & {$[47]$} \\
\hline $\mathrm{N}$-methyltransferase & $\begin{array}{l}\text { - Sphere formation } \\
\text { - Expression of CD133, CD44, Oct4, Sox2, Nanog, Nestin, } \\
\text { ABCG2, and BMI-1 }\end{array}$ & - MG-63 human cell line & {$[48]$} \\
\hline $\mathrm{m}^{6} \mathrm{~A}$ methylome & $\begin{array}{l}\text { - Multidrug resistance } \\
\text { - Sphere formation } \\
\text { - Overexpression of CD117, stro-1, CD113, and stemness } \\
\text { markers (SOX2, POU5F1, NANOG, KLF4) } \\
\text { - Upregulation of METTL3 and ALKBH5 and } \\
\text { downregulation of METTL14 and FTO }\end{array}$ & - MG63 human cell line & [49] \\
\hline
\end{tabular}




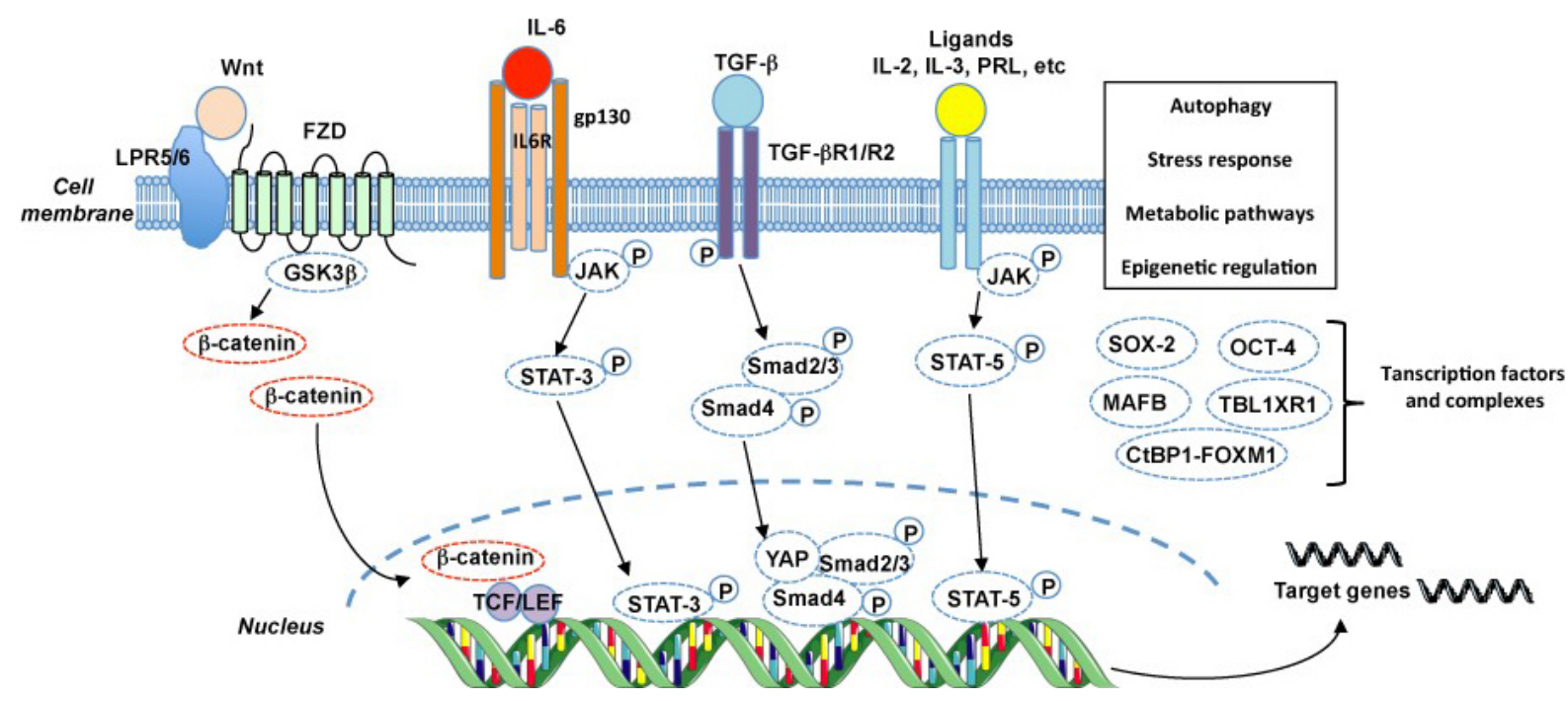

Figure 1. Main signaling pathways and mechanisms regulating the maintenance of cancer stem-like cells in osteosarcoma. LPR: Lipoprotein receptor-related protein; FZD: frizzled receptor; PRL: prolactin receptor.

hedgehog $(\mathrm{IHH})$ signaling in cartilage and bone tumors by deleting Ptch1 encoding an inhibitor of IHH receptor. They demonstrated that deleting Ptch 1 in mice was associated with an increase in Wnt member expression and the development of skeletal diseases, including osteosarcoma. Interestingly, inhibiting the $\mathrm{Wnt} / \beta$-catenin pathway abolished the development of osteosarcoma, highlighting the key role played by this molecular pathway in the pathogenesis of bone sarcomas ${ }^{[58]}$. The Wnt/ $\beta$-catenin pathway might be the link among tumor development, drug resistance, and CSCs in osteosarcoma. Whether or not the Wnt/ $\beta$-catenin cascade was related to chemoresistance, it appeared to be a driver of cancer by acting directly on tumor cells, but also by modulating the immune microenvironment ${ }^{[59]}$. This cancer driver is persistently activated in the CSCs of osteosarcoma, and the stemness properties induced by chemotherapies are related to activation of the $\mathrm{Wnt} / \beta$-catenin cascade ${ }^{[43,60,61]}$. In this context, most molecular machineries that modulate the expression level of Wnt/ $\beta$-catenin may affect cancer cell behavior. Thus, epigenetic regulation of Wnt/ $\beta$ catenin using the lncRNA DLX6-AS1/miR-129-5p/DLK1 axis or histone methyltransferase SETD2 results in increased stemness properties for osteosarcoma cells, tumor growth, and drug resistance ${ }^{[62,63]}$. The key contribution of Wnt/ $\beta$-catenin in the maintenance of CSCs may lead to the development of new targeted therapies in osteosarcoma, as described below.

IL-6/STAT3 signaling has also been identified as a crucial regulator of bone remodeling and primary bone tumors $^{[64]}$. The IL- 6 family of cytokines, composed of 10 members including IL-11, OSM, and LIF, induces redundant and pleiotropic activities such as embryogenesis, differentiation, or inflammation. Most of the members of this family share the transducing receptor $\beta$-subunit gp130 as part of a multimeric receptor complex that includes a specific receptor $\alpha$-subunit (e.g., IL-6R). The oligomerization of receptor subunits induced by each ligand results in various transductions of signaling pathways dominated by JAK/STAT3 activation and others such as MAPKs, p38, and JNK [Figure 1]. In addition to its functions on the tumor microenvironment (e.g., bone and immune cells), the IL-6 signaling pathway controls the maintenance of CSCs in osteosarcoma ${ }^{[65]}$. IL-6 released by activated mesenchymal stem cells (MSCs) in the tumor microenvironment promoted osteosarcoma stemness and the spreading properties of cancer cells ${ }^{[65]}$. In addition, MSCs supported drug resistance through STAT-3 signaling in cancer cells activated by IL- $6^{[6]]}$. MSCs and osteosarcoma cells then established a reciprocal dialog initiated by TGF- $\beta$ containing extracellular vesicles secreted by cancer cells that induced the production of IL- 6 by MSCs, which in turn 
supported stemness, drug resistance, and tumor progression ${ }^{[67]}$. The use of active drugs confirmed the contribution of the IL-6/STAT3 axis in osteosarcoma stemness ${ }^{[68,69]}$.

The TGF- $\varangle /$ Smad axis regulates the self-renewal of osteosarcoma cells. TGF- $\beta$ belongs to a large family of at least 30 secreted proteins sharing structural similarities. TGF- $\beta$ growth factors are secreted as latent precursors which can bind to specific receptor chains after activation in mature form. TGF- $\beta$ induces the assembly of type I and II TGF- $\beta$ receptors, leading to the formation of heteromeric receptors and the initiation of the signal transduction. The type I TGF- $\beta$ receptor shows intrinsic tyrosine kinase activity, phosphorylates the type II chain, and initiates the downstream signaling, which includes Smads phosphorylation. Phospho-Smads complexes are translocated into the nucleus where they cooperate with YAP/TAZ transcription regulators and modulate the transcription of target genes [Figure 1]. Zhang et al. ${ }^{[70]}$ studied the functional impact of TGF- $\beta 1$ on osteosarcoma stemness in a hypoxic environment. They demonstrated the crucial role played by TGF- $\beta 1$ on the proliferative state of cancer cells, which acquired the stem cell phenotype for self-renewal, drug resistance, neoangiogeneiss, and tumorigenicity; on the contrary, blocking the TGF- $\beta 1$ signaling pathway reduced the dedifferentiation program of osteosarcoma cells. Similarly, by using gamabufotalin, a bufadienolide extracted from toad venom, it has recently been demonstrated that blockading the TGF- $\beta$ /periostin/PI3K/AKT axis resulted in suppression of CSCs in osteosarcoma $^{[71]}$. CSCs associated with TGF- $\beta$ activity were also linked to drug resistance, as shown for EGFR inhibitors, highlighting once again the role played by CSCs in the drug resistance process ${ }^{[72]}$.

Recently, a series of transcription factors were identified as regulators of cancer stemness in osteosarcoma. The transcription factor Sox determining the region Y-box 2 (Sox2) plays a key role in developing and controlling the embryonic stem cell state and was identified as a biomarker for CSCs in osteosarcoma [Table 1]. In addition, the proliferation of osteosarcoma cells and tumor development requires Sox $2^{[73]}$. Maurizi et al. ${ }^{[73]}$ compared tumor growth in Cre-bearing mice with identical $\mathrm{Rb}$ and $\mathrm{p} 53$ genotypes in a background of Sox2-deficient or wild-type mice. Tumor development was significantly slowed down in the Sox2-deficient mice compared to the other groups, and the survival rate was also higher in the Sox 2 knockout mice. Sox 2 appeared essential for the survival and proliferation of all osteosarcoma cells, including CSCs. The Hippo pathway, which is under the transcriptional control of Sox2, was directly related to the same activities, and deactivating Sox2 effectors (e.g., YAP) resulted similarly in a reduction in tumor growth $^{[73]}$. Chen et al. ${ }^{[74]}$ demonstrated that musculoaponeurotic fibrosarcoma oncogene homolog B (MAFB) is highly expressed in osteosarcoma and more specifically in CSCs, and this transcription factor, similar to Sox2, is required for the proliferation and tumorigenicity of osteosarcoma cells. Interestingly, they observed that maintaining the self-renewal potential of CSCs was under the transcriptional control of Sox-9, a stem cell regulator ${ }^{[74]}$. More recently, STAT-5 associated signaling was identified as a key regulator ${ }^{[75]}$. The knockdown of STAT-5 (A and B isoforms) using an siRNA approach reduced pimozide-induced tumor growth in mice, in addition to suppressing in vitro sphere formation. Inhibiting STAT-5 signaling thus impaired osteosarcoma self-renewal and development ${ }^{[75]}$. JAK/STAT-5 activation belongs to the downstream signaling associated with various cytokine/hormone-induced signaling pathways, including prolactin, IL-2, IL-3, etc. Oct4 promoted osteosarcoma development by supporting the maintenance of CSCs through the increase in AK055347, a long-noncoding (lnc) RNA. Oct4 knockdown with siRNA induced a significant decrease in cell proliferation, invasion, and apoptosis ${ }^{[76]}$. TBL1XR1 is a transcriptional co-factor which is overexpressed in osteosarcoma patients ${ }^{[77]}$. Its overexpression in MG63 and U2-OS cell lines induced a CSC phenotype in contrast to its repression. TBL1XR1 thus provides osteosarcoma cells with tumorigenic properties and promotes the recurrence of osteosarcoma in a STAT-3 signaling dependent manner ${ }^{[77]}$. Transcriptional complexes can also modulate osteosarcoma drug resistance. Thus, the CtBP1FOXM1 transcriptional complex increased MDR1 expression in osteosarcoma CSCs, which is associated 
with drug resistance ${ }^{[78]}$. Interestingly, small molecules targeting this complex reversed the MDR1-mediated resistance both in vitro and in murine preclinical models.

Regulating osteosarcoma growth through the oct4/lncRNA axis highlights the epigenetic regulation of osteosarcoma CSCs ${ }^{[79]}$. This observation is supported by the rich literature emerging in the last 10 years ${ }^{[76]}$ [Table 1]. In this context, chromodomain helicase DNA binding protein 1-like significantly reduced osteosarcoma proliferation and drug resistance though its binding to DNA. It also controls chromosomal integrity maintenance, DNA repair, and transcriptional regulation ${ }^{[79]}$. Ubiquitin-specific peptidase 39 is a crucial factor for assembling mature spliceosome complex, and its knockdown leads to the inhibition of osteosarcoma cell proliferation combined with an increase in apoptosis ${ }^{[80]}$. Human antigen $\mathrm{R}$ is involved in stabilizing mRNA, and its repression in osteosarcoma cells reduced their stemness properties and increased the drug response $\mathrm{e}^{[81]}$. These activities were related to YAP activation. Several recent publications showed the role played by specific miRNA in controlling stemness in osteosarcoma, including miR29b and its target Spin ${ }^{[82]}$, miR34a ${ }^{[83]}$ and the DNMT1/miR34a/Bcl2 axis ${ }^{[84,85]}$, TNF- $\alpha-$ miR155 signaling ${ }^{[86]}$, miR335 and its target POUF5 ${ }^{[87]}$, miR429 and its target Sox $2^{[88]}$, and the TGF- $\beta /$ miR499a/SHKBP1 89 axis $^{[89,90]}$. Very recently, leukemia inhibitory factor (LIF) was shown to belong to the IL-6 family of cytokines, similarly activating STAT-3, and was recently revealed as a super-enhancer-controlled regulator of CSC properties, confirming the role of STAT-3 transcription factor in the functional regulation of CSCs in osteosarcoma ${ }^{[1]}$. TSSC3 tumor-suppressing STF cDNA 3 (TSSC3), the first apoptosis-related gene reported to be imprinted, repressed the self-renewal of osteosarcoma $\operatorname{CSCs}^{[92]}$. Finally, $\operatorname{lncRNAs}$ also play a part in the biological regulation of CSCs in osteosarcoma ${ }^{[76,92,93]}$.

Autophagy ${ }^{[4,95]}$, stress response ${ }^{[96-98]}$, and numerous enzymatic pathways ${ }^{[99-104]}$ complete the landscape of the osteosarcoma CSC regulation mode. Autophagy was shown as a critical biological process for maintaining CSCs in $\mathrm{OS}^{[94]}$, and defective autophagy was directly associated with the decrease in $\mathrm{CSCs}^{[95]}$. Similarly, the knockdown of stress-induced phosphoprotein 1 resulted in the inhibition of CSC invasiveness and migration ${ }^{[96]}$. STIP- 1 is a co-chaperone that binds to HSP70 and -90 and consequently inhibits Hsp90 by 17AAG-reduced stem cell-like properties and decreased drug resistance in $\mathrm{OS}^{[97]}$.

\section{THERAPEUTIC TARGETING OF CANCER STEM-LIKE CELLS IN OSTEOSARCOMA}

The recent evidence of CSCs in osteosarcoma and better understanding of the molecular pathways required for their maintenance, led to the identification of new therapeutic targets, as summarized in Table 2.

Repressing the signaling pathways related to the maintenance of CSCs (see Table 1) resulted in the slowdown of tumor growth and inhibition of the metastatic process ${ }^{[105-116]}$. As previously mentioned, Wnt $/ \beta$ catenin appeared crucial for the maintenance of CSCs and its attenuation by using tankyrase inhibitor, or tegavivint was associated with a decrease in both CSC numbers and tumor progression ${ }^{[105,106]}$. GSK3 appeared highly expressed in osteosarcoma and targeting Akt/GSK3/ $\beta$-catenin or Akt/GSK3-/Notch-1, respectively, with dioscein or tideglusib repressed CSC and tumor growth ${ }^{[107,108]}$. Gamabufotalin-induced similar activities by targeting TGF- $\beta$ /periostin/PI3K/Akt signaling as it has been shown for hepatocarcinoma ${ }^{[71,109]}$. Similar results were obtained by targeting $\mathrm{BMP}_{2} \mathrm{R}^{[110]}$. Drugs targeting transcription factors (e.g., STAT-3 and STAT5) controlling the development of CSCs may also be used to improve the therapeutic approaches to osteosarcoma ${ }^{[75,111,112]}$. Activation of hormone signaling can reduce stemness in osteosarcoma, as shown by the activation of estrogen receptor alpha by decitabine ${ }^{[113]}$. Most cytokineinduced signaling pathways result in the translocation of transcription factors which modulate the transcription of target genes. Targeting of such transcription factors (e.g., KLF4 and Sox9) may be used for reducing CSCs in osteosarcoma ${ }^{[114-116]}$. Similarly, ROCK inhibition by fasudil suppressed in vitro cell 
Table 2. Potential therapeutic approach to CSCs in osteosarcoma

\begin{tabular}{|c|c|c|}
\hline Drug & Molecular pathway involved or therapeutic approaches & Ref. \\
\hline \multicolumn{3}{|l|}{ Wnt/ $\beta$-catenin targeting } \\
\hline Tankyrase inhibitor (IWR-1) & Attenuation of Wnt/ $\beta$-catenin signaling & {$[105]$} \\
\hline Tegavivint & $\beta$-catenin/transducing $\beta$-like protein 1 (TBL1) inhibition & [106] \\
\hline Dioscein & Akt/GSK3/ $\beta$-catenin & [107] \\
\hline Tideglusib & GSK-3ß/NOTCH1 & [108] \\
\hline \multicolumn{3}{|l|}{ TGF- $\beta /$ BMP2 targeting } \\
\hline Gamabufotalin & TGF- $\beta /$ periostin/PI3K/AKT & [109] \\
\hline BMP2 & BMP2 receptor signaling & [110] \\
\hline \multicolumn{3}{|c|}{ Other receptor signaling targeting (STAT-3, STAT-5, ER- $\alpha$, TRAF-2, etc.) and transcription factors } \\
\hline Bruceine D & STAT-3 inhibition & [111] \\
\hline Pimozide & STAT-5 signaling & {$[75,112]$} \\
\hline Decitabine & Activation of estrogen receptor alpha $(E R-\alpha)$ & [113] \\
\hline NCB-0846 & TRAF2- and NCK-interacting protein kinase & [114] \\
\hline Melatonin & Suppression of SOX9 mediated signaling & [115] \\
\hline Statins & KLF4 & [116] \\
\hline \multicolumn{3}{|l|}{ Targeting of kinase activities } \\
\hline Fasudil & Rho-associated coiled-coil containing kinase (ROCK) inhibition & {$[100]$} \\
\hline \multicolumn{3}{|l|}{ Autophagy and metabolic targeting } \\
\hline Thioridazine & Autophagy & [94] \\
\hline \multirow[t]{4}{*}{ Metfomin } & $\begin{array}{l}\text { - Inhibition of mitochondrial functions (decrease in oxygen assumption, decreased } \\
\text { mitochondrial membrane potential, decreased ATP production) }\end{array}$ & [117] \\
\hline & - Pyruvate kinase isoenzyme M2 (PKM2) & [118] \\
\hline & - ROS-mediated apoptosis and autophagy & [119] \\
\hline & - Activation and phosphorylation of the energetic sensor AMPK & [120] \\
\hline Wogonin & ROS regulation & [121] \\
\hline DMAMCL & Cell cycle & [122] \\
\hline DAPT & $\gamma$-secretase inhibition & [123] \\
\hline \multicolumn{3}{|c|}{ Combinations with chemotherapy and sensitization to chemotherapy } \\
\hline Ascorbate & Sensitization to cisplatin & [124] \\
\hline Ouabain & Sensitization to cisplatin: $\mathrm{Na}^{+} / \mathrm{K}^{+}$ATPase inhibition & [125] \\
\hline $\begin{array}{l}\text { Tangeretin-assisted platinum } \\
\text { nanoparticles }\end{array}$ & Combination with doxorubucin & [126] \\
\hline Senolytic drug (Fisetin) & Combination with etoposide & [127] \\
\hline \multicolumn{3}{|l|}{ Immunotherapy } \\
\hline $\begin{array}{l}\text { Immunotherapy based on cytokine } \\
\text { induced killer cells }\end{array}$ & CSCs spared after chemotherapy or other targeted therapies & {$[128,129]$} \\
\hline \multicolumn{3}{|l|}{ Modulation of epigenetic events } \\
\hline \multirow[t]{6}{*}{ Epigenetic targeting } & - USP39 silencing & {$[80]$} \\
\hline & - HuR knockdown & {$[81]$} \\
\hline & - Disruption of the DNMT1/miR34a/Bcl-2 axis by isovitexin & {$[85]$} \\
\hline & - IncRNA HOXD-AS1 knockdown & [92] \\
\hline & - RAB39A silencing & [99] \\
\hline & - Targeting of IncRNA SOX2OT variant 7 by EGCG (polyphenol isolated from green tea) & [130] \\
\hline \multicolumn{3}{|l|}{ Photo therapy } \\
\hline $\begin{array}{l}\text { - Graphene oxide nanoparticle-loaded } \\
\text { ginsenoside Rg3 }\end{array}$ & Photodynamic therapy & [131] \\
\hline - CD271 antibody-functionalized HGNs & Photothermal therapy & [132] \\
\hline
\end{tabular}

\section{Drug delivery systems}


proliferation and reduced their tumorigeneicity in $v i v o^{[100]}$. Cell metabolism is significantly modulated in CSCs (e.g., autophagy and cell cycle), and these specificities can be used for targeting CSCs in osteosarcoma. For instance, thioridazin and metformin target autophagy and metformin and wogomin modulated ROSmediated apoptosis in CSCs and resensitize CSCs to cell death ${ }^{[114-116]}$. Similarly, regulation of cell cycle by DMAMCL or inhibition of $\gamma$-secretase by DAPT affects the behavior of CSCs and their function in tumor growth $^{[122,123]}$.

Drugs/effective agents can be used as sensitization agents to chemotherapy ${ }^{[124,125]}$ or in combination with chemotherapeutic drugs ${ }^{[126,127]}$. Numerous cytokines are involved in the control of local immunity of cancer cells ${ }^{[128]}$ and immunotherapies have been proposed for targeting CTCs ${ }^{[129]}$. Specific silencing of the epigenetic partners of CSCs can induce similar regression in tumor growth and metastatic development by altering CSC maintenance ${ }^{[80,81,92,95,99,129]}$. Nanoparticles can be used for developing phototherapies and drug delivery systems. In this context, nanoparticles have been functionalized and adapted for phototherapy with a specific aim to improve the targeting of CSCs using ${ }^{[131,132]}$. Finally, drug delivery systems have also been proposed $^{[133-135]}$. For all these therapeutic approaches, the question of the general toxicity in healthy tissue stem cells and the specificity of the targeting remains unanswered.

\section{CONCLUSION}

Long considered as controversial, today CSCs are a realistic therapeutic target in osteosarcoma ${ }^{[1,2]}$. Osteosarcoma remains a highly heterogeneous oncological entity in perpetual evolution due to a strong clonal dynamic ${ }^{[136]}$, leading to very efficient adaptation to drugs and the establishment of drug resistance ${ }^{[15]}$. The dynamic properties of tumor evolution have led to numerous questions about CSCs and their functional impact: (1) Can we detect CSCs in the bloodstream and can we use circulating tumor cells to follow the minimal residual disease and identify personalized therapeutic option ${ }^{[137]}$ ? (2) Are CSCs capable of migrating to distant organs to establish metastatic foci? (3) Is the dynamic evolution of osteosarcoma similar in the primary site and in the metastatic foci? (4) What is the functional regulation of CSCs and are they under the control of proliferating osteosarcoma cells? (5) Are CSCs regulated by the tumor microenvironment and by which molecular pathways? (6) Can we use immune therapies in combination with other drugs (e.g., chemotherapy) to target CSCs and improve overall survival in osteosarcoma? (7) How can we specifically control CSC metabolism and consequently can we set up specific therapeutic options to control CSC wake-up? (8) As osteosarcoma is a form of cancer that originates in the mesenchyme, can we use the fibrogenic reprogramming of CSCs as a therapeutic option ${ }^{[138]}$ ? Even whether sarcomas being considered as an immune desert explaining the current poor clinical efficacy of immune therapies needs more research ${ }^{[1,128]}$, macrophage and stromal cells contribute to the establishment of drug resistance and may be identified as therapeutic target in osteosarcoma ${ }^{[139]}$. For instance, M2 macrophage may be associated with tumor angiogenesis. Tumor cells release a high number of protons that induce local acidosis, favoring the release of inflammatory mediators by local stromal cells, which in turn facilitates tumor invasiveness and metastasis in osteosarcoma ${ }^{[140]}$. Overall, it has been demonstrated that stromal cells significantly contribute to increase the stemness properties of osteosarcoma cells by inducing metabolic reprogramming of cancer cells ${ }^{[14,142]}$. Consequently, stromal cells constitute an interesting reservoir of stemness targeting to reduce osteosarcoma progression, as has been shown recently ${ }^{[143]}$. A better 
understanding of the role of stromal cells in the control of stemness would help to identify new mediators associated with stemness, drug resistance, and tumor progression. Overall, CSCs are promising targets in osteosarcoma, as demonstrated by the most recent data described in this review, paving the way for a new therapeutic era focused on better-controlled residual disease in osteosarcoma through targeting CSCs.

\section{DECLARATIONS}

\section{Authors' contributions}

Supervised the work proposed and took the lead in writing the manuscript: Heymann D

Contributed to the preparation of the manuscript: Jubelin C, Muñoz-Garcia J, Cochonneau D, Moranton E, Heymann MF

All authors approved the final version submitted.

\section{Availability of data and materials}

Not applicable.

\section{Financial support and sponsorship}

This work was supported by an internal ICO grant 2018 (ref\# "DorSarc-2018-ICO-DH”).

\section{Conflicts of interest}

Jubelin C is an employee of Atlantic Bone Screen and prepared her $\mathrm{PhD}$ at the Université de Nantes (FR). Heymann D is a member of the Editorial board of Cancer Drug Resistance.

\section{Ethical approval and consent to participate}

Not applicable.

\section{Consent for publication}

Not applicable.

\section{Copyright}

(c) The Author(s) 2022.

\section{REFERENCES}

1. Grünewald TG, Alonso M, Avnet S, et al. Sarcoma treatment in the era of molecular medicine. EMBO Mol Med 2020;12:e11131. DOI PubMed PMC

2. Brown HK, Schiavone K, Gouin F, Heymann MF, Heymann D. Biology of bone sarcomas and new therapeutic developments. Calcif Tissue Int 2018;102:174-95. DOI PubMed PMC

3. Baumhoer D, Böhling TO, Cates JMM, et al. Osteosarcoma. WHO Classification of Tumours Editorial board. Soft tissue and bone tumours. Lyon (France): International Agency for Research on Cancer; 2020. p. 403-9.

4. Flanagan AM, Bridge JA, O’Donnel PG. Secondary osteosarcoma. WHO Classification of Tumours Editorial board. Soft tissue and bone tumours. Lyon (France): International Agency for Research on Cancer; 2020. p. 419-21.

5. Gill J, Gorlick R. Advancing therapy for osteosarcoma. Nat Rev Clin Oncol 2021;18:609-24. DOI PubMed

6. Strauss SJ, Whelan JS. Current questions in bone sarcomas. Curr Opin Oncol 2018;30:252-9. DOI PubMed

7. Sarcoma Network Working Group. Bone sarcomas: ESMO Clinical Practice Guidelines for diagnosis, treatment and follow-up. Ann Oncol 2012;23 Suppl 7:vii100-9. DOI

8. Kovac M, Blattmann C, Ribi S, et al. Exome sequencing of osteosarcoma reveals mutation signatures reminiscent of BRCA deficiency. Nat Commun 2015;6:8940. DOI PubMed PMC

9. Behjati S, Tarpey PS, Haase K, et al. Recurrent mutation of IGF signalling genes and distinct patterns of genomic rearrangement in osteosarcoma. Nat Commun 2017;8:15936. DOI PubMed PMC

10. Wu SP, Cooper BT, Bu F, et al. DNA methylation-based classifier for accurate molecular diagnosis of bone sarcomas. JCO Precis Oncol 2017:2017. DOI PubMed PMC

11. Morrow JJ, Bayles I, Funnell APW, et al. Positively selected enhancer elements endow osteosarcoma cells with metastatic competence. Nat Med 2018;24:176-85. DOI PubMed PMC

12. Asano N, Takeshima H, Yamashita S, et al. Epigenetic reprogramming underlies efficacy of DNA demethylation therapy in osteosarcomas. Sci Rep 2019;9:20360. DOI PubMed PMC 
13. Brown HK, Tellez-Gabriel M, Cartron PF, Vallette FM, Heymann MF, Heymann D. Characterization of circulating tumor cells as a reflection of the tumor heterogeneity: myth or reality? Drug Discov Today 2019;24:763-72. DOI PubMed

14. Tellez-Gabriel M, Heymann MF, Heymann D. Circulating tumor cells as a tool for assessing tumor heterogeneity. Theranostics 2019;9:4580-94. DOI PubMed PMC

15. Vallette FM, Olivier C, Lézot F, et al. Dormant, quiescent, tolerant and persister cells: four synonyms for the same target in cancer. Biochem Pharmacol 2019;162:169-76. DOI PubMed

16. Nassar D, Blanpain C. Cancer stem cells: basic concepts and therapeutic implications. Annu Rev Pathol 2016;11:47-76. DOI PubMed

17. Walcher L, Kistenmacher AK, Suo H, et al. Cancer stem cells-origins and biomarkers: perspectives for targeted personalized therapies. Front Immunol 2020;11:1280. DOI PubMed PMC

18. Clarke MF. Clinical and therapeutic implications of cancer stem cells. N Engl J Med 2019;380:2237-45. DOI PubMed

19. Halldorsson A, Brooks S, Montgomery S, Graham S. Lung metastasis 21 years after initial diagnosis of osteosarcoma: a case report. $J$ Med Case Rep 2009;3:9298. DOI PubMed PMC

20. Perrot P, Rousseau J, Bouffaut AL, et al. Safety concern between autologous fat graft, mesenchymal stem cell and osteosarcoma recurrence. PLoS One 2010;5:e10999. DOI PubMed PMC

21. Pantel K, Alix-Panabières C. Tumour microenvironment: informing on minimal residual disease in solid tumours. Nat Rev Clin Oncol 2017;14:325-6. DOI PubMed

22. Ferrari S, Bacci G, Picci P, et al. Long-term follow-up and post-relapse survival in patients with non-metastatic osteosarcoma of the extremity treated with neoadjuvant chemotherapy. Ann Oncol 1997;8:765-71. DOI PubMed

23. Bielack SS, Kempf-Bielack B, Delling G, et al. Prognostic factors in high-grade osteosarcoma of the extremities or trunk: an analysis of 1,702 patients treated on neoadjuvant cooperative osteosarcoma study group protocols. J Clin Oncol 2002;20:776-90. DOI PubMed

24. Smeland S, Bielack SS, Whelan J, et al. Survival and prognosis with osteosarcoma: outcomes in more than 2000 patients in the EURAMOS-1 (European and American Osteosarcoma Study) cohort. Eur J Cancer 2019;109:36-50. DOI PubMed PMC

25. Pennati A, Riggio E, Marano G, Biganzoli E. Autologous fat grafting after sarcoma surgery: evaluation of oncological safety. J Plast Reconstr Aesthet Surg 2018;71:1723-9. DOI PubMed

26. Le Nail LR, Brennan M, Rosset P, et al. Comparison of tumor- and bone marrow-derived mesenchymal stromal/stem cells from patients with high-grade osteosarcoma. Int J Mol Sci 2018;19:707. DOI PubMed PMC

27. Zhou Z, Li Y, Kuang M, et al. The CD24 cell subset promotes invasion and metastasis in human osteosarcoma. EBioMedicine 2020;51:102598. DOI PubMed PMC

28. Shao XJ, Xiang SF, Chen YQ, et al. Inhibition of M2-like macrophages by all-trans retinoic acid prevents cancer initiation and stemness in osteosarcoma cells. Acta Pharmacol Sin 2019;40:1343-50. DOI PubMed PMC

29. Adhikari AS, Agarwal N, Wood BM, et al. CD117 and Stro-1 identify osteosarcoma tumor-initiating cells associated with metastasis and drug resistance. Cancer Res 2010;70:4602-12. DOI PubMed PMC

30. Tang QL, Liang Y, Xie XB, et al. Enrichment of osteosarcoma stem cells by chemotherapy. Chin J Cancer 2011;30:426-32. DOI PubMed PMC

31. Yu L, Liu S, Zhang C, et al. Enrichment of human osteosarcoma stem cells based on hTERT transcriptional activity. Oncotarget 2013;4:2326-38. DOI PubMed PMC

32. Tirino V, Desiderio V, d'Aquino R, et al. Detection and characterization of CD133+ cancer stem cells in human solid tumours. PLoS One 2008;3:e3469. DOI PubMed PMC

33. Tirino V, Desiderio V, Paino F, et al. Human primary bone sarcomas contain CD133+ cancer stem cells displaying high tumorigenicity in vivo. FASEB J 2011;25:2022-30. DOI PubMed

34. He A, Qi W, Huang Y, et al. CD133 expression predicts lung metastasis and poor prognosis in osteosarcoma patients: a clinical and experimental study. Exp Ther Med 2012;4:435-41. DOI PubMed PMC

35. Li J, Zhong XY, Li ZY, et al. CD133 expression in osteosarcoma and derivation of CD133 ${ }^{+}$cells. Mol Med Rep 2013;7:577-84. DOI PubMed

36. Ozturk S, Gorgun C, Gokalp S, Vatansever S, Sendemir A. Development and characterization of cancer stem cell-based tumoroids as an osteosarcoma model. Biotechnol Bioeng 2020;117:2527-39. DOI PubMed

37. Fujiwara T, Katsuda T, Hagiwara K, et al. Clinical relevance and therapeutic significance of microRNA-133a expression profiles and functions in malignant osteosarcoma-initiating cells. Stem Cells 2014;32:959-73. DOI PubMed

38. Mardani A, Gheytanchi E, Mousavie SH, Madjd Jabari Z, Shooshtarizadeh T. Clinical significance of cancer stem cell markers CD133 and CXCR4 in osteosarcomas. Asian Pac J Cancer Prev 2020;21:67-73. DOI PubMed PMC

39. Bao Z, Cheng Z, Chai D. The expressions of CD133, ALDH1, and vasculogenic mimicry in osteosarcoma and their clinical significance. Int J Clin Exp Pathol 2018;11:3656-63. PubMed PMC

40. Tian J, Li X, Si M, Liu T, Li J. CD271+ osteosarcoma cells display stem-like properties. PLoS One 2014;9:e98549. DOI PubMed PMC

41. Honoki K, Fujii H, Kubo A, et al. Possible involvement of stem-like populations with elevated ALDH1 in sarcomas for chemotherapeutic drug resistance. Oncol Rep 2010;24:501-5. DOI PubMed

42. Wang L, Park P, Zhang H, La Marca F, Lin CY. Prospective identification of tumorigenic osteosarcoma cancer stem cells in OS99-1 cells based on high aldehyde dehydrogenase activity. Int J Cancer 2011;128:294-303. DOI PubMed

43. Martins-Neves SR, Paiva-Oliveira DI, Wijers-Koster PM, et al. Chemotherapy induces stemness in osteosarcoma cells through 
activation of Wnt/ $\beta$-catenin signaling. Cancer Lett 2016;370:286-95. DOI PubMed

44. Wang F, Zhang Z, Li Q, Yu T, Ma C. Untargeted LC-MS/MS analysis reveals metabolomics feature of osteosarcoma stem cell response to methotrexate. Cancer Cell Int 2020;20:269. DOI PubMed PMC

45. Mizushima E, Tsukahara T, Emori M, et al. Osteosarcoma-initiating cells show high aerobic glycolysis and attenuation of oxidative phosphorylation mediated by LIN28B. Cancer Sci 2020;111:36-46. DOI PubMed PMC

46. Zhong Z, Mao S, Lin H, Li H, Lin J, Lin JM. Alteration of intracellular metabolome in osteosarcoma stem cells revealed by liquid chromatography-tandem mass spectrometry. Talanta 2019;204:6-12. DOI PubMed

47. Koka P, Mundre RS, Rangarajan R, Chandramohan Y, Subramanian RK, Dhanasekaran A. Uncoupling Warburg effect and stemness in CD133 ${ }^{+v e}$ cancer stem cells from Saos-2 (osteosarcoma) cell line under hypoxia. Mol Biol Rep 2018;45:1653-62. DOI PubMed

48. Pozzi V, Salvolini E, Lucarini G, et al. Cancer stem cell enrichment is associated with enhancement of nicotinamide Nmethyltransferase expression. IUBMB Life 2020;72:1415-25. DOI PubMed

49. Wang Y, Zeng L, Liang C, et al. Integrated analysis of transcriptome-wide $\mathrm{m}^{6} \mathrm{~A}$ methylome of osteosarcoma stem cells enriched by chemotherapy. Epigenomics 2019;11:1693-715. DOI PubMed

50. Menéndez ST, Gallego B, Murillo D, Rodríguez A, Rodríguez R. Cancer stem cells as a source of drug resistance in bone sarcomas. $J$ Clin Med 2021;10:2621. DOI PubMed PMC

51. Belayneh R, Weiss K. The role of aldh in the metastatic potential of osteosarcoma cells and potential ALDH targets. In: Kleinerman ES, Gorlick R, editors. Current advances in the science of osteosarcoma. Cham: Springer International Publishing; 2020. p. 157-66. DOI PubMed

52. Tsuchida R, Das B, Yeger H, et al. Cisplatin treatment increases survival and expansion of a highly tumorigenic side-population fraction by upregulating VEGF/Flt1 autocrine signaling. Oncogene 2008;27:3923-34. DOI PubMed

53. Sun DX, Liao GJ, Liu KG, Jian H. Endosialin-expressing bone sarcoma stem-like cells are highly tumor-initiating and invasive. Mol Med Rep 2015;12:5665-70. DOI PubMed PMC

54. Di Fiore R, Santulli A, Ferrante RD, et al. Identification and expansion of human osteosarcoma-cancer-stem cells by long-term 3aminobenzamide treatment. J Cell Physiol 2009;219:301-13. DOI PubMed

55. Roundhill EA, Chicon-Bosch M, Jeys L, et al. RNA sequencing and functional studies of patient-derived cells reveal that neurexin-1 and regulators of this pathway are associated with poor outcomes in Ewing sarcoma. Cell Oncol (Dordr) 2021;44:1065-85. DOI PubMed PMC

56. Alfranca A, Martinez-Cruzado L, Tornin J, et al. Bone microenvironment signals in osteosarcoma development. Cell Mol Life Sci 2015;72:3097-113. DOI PubMed

57. Danieau G, Morice S, Rédini F, et al. New insights about Wnt/beta-catenin signaling pathway in primary bone tumors and their microenvironment: a promising target to develop therapeutic strategies? Int J Mol Sci 2019;20:3751. DOI PubMed PMC

58. Deng Q, Li P, Che M, et al. Activation of hedgehog signaling in mesenchymal stem cells induces cartilage and bone tumor formation via Wnt/ $\beta$-Catenin. Elife 2019;8:e50208. DOI PubMed PMC

59. Parsons MJ, Tammela T, Dow LE. WNT as a driver and dependency in cancer. Cancer Discov 2021;11:2413-29. DOI PubMed PMC

60. Martins-Neves SR, Corver WE, Paiva-Oliveira DI, et al. Osteosarcoma stem cells have active Wnt/ $\beta$-catenin and overexpress SOX2 and KLF4. J Cell Physiol 2016;231:876-86. DOI PubMed

61. Martins-Neves SR, Cleton-Jansen AM, Gomes CMF. Therapy-induced enrichment of cancer stem-like cells in solid human tumors: where do we stand? Pharmacol Res 2018;137:193-204. DOI PubMed

62. Zhang RM, Tang T, Yu HM, et al. LncRNA DLX6-AS1/miR-129-5p/DLK1 axis aggravates stemness of osteosarcoma through Wnt signaling. Biochem Biophys Res Commun 2018;507:260-6. DOI PubMed

63. Jiang C, He C, Wu Z, Li F, Xiao J. Histone methyltransferase SETD2 regulates osteosarcoma cell growth and chemosensitivity by suppressing Wnt/ $\beta$-catenin signaling. Biochem Biophys Res Commun 2018;502:382-8. DOI PubMed

64. Blanchard F, Duplomb L, Baud'huin M, Brounais B. The dual role of IL-6-type cytokines on bone remodeling and bone tumors. Cytokine Growth Factor Rev 2009;20:19-28. DOI PubMed

65. Cortini M, Massa A, Avnet S, Bonuccelli G, Baldini N. Tumor-activated mesenchymal stromal cells promote osteosarcoma stemness and migratory potential via IL-6 secretion. PLoS One 2016;11:e0166500. DOI PubMed PMC

66. Tu B, Zhu J, Liu S, et al. Mesenchymal stem cells promote osteosarcoma cell survival and drug resistance through activation of STAT3. Oncotarget 2016;7:48296-308. DOI PubMed PMC

67. Baglio SR, Lagerweij T, Pérez-Lanzón M, et al. Blocking tumor-educated MSC paracrine activity halts osteosarcoma progression. Clin Cancer Res 2017;23:3721-33. DOI PubMed

68. Zhang C, Ma K, Li WY. Cinobufagin suppresses the characteristics of osteosarcoma cancer cells by inhibiting the IL-6-OPN-STAT3 Pathway. Drug Des Devel Ther 2019;13:4075-90. DOI PubMed PMC

69. Tian ZC, Wang JQ, Ge H. Apatinib ameliorates doxorubicin-induced migration and cancer stemness of osteosarcoma cells by inhibiting Sox2 via STAT3 signalling. J Orthop Translat 2019;22:132-41. DOI PubMed PMC

70. Zhang $\mathrm{H}, \mathrm{Wu} \mathrm{H}$, Zheng J, et al. Transforming growth factor $\beta 1$ signal is crucial for dedifferentiation of cancer cells to cancer stem cells in osteosarcoma. Stem Cells 2013;31:433-46. DOI PubMed

71. Ma K, Zhang C, Li W. Gamabufotalin suppressed osteosarcoma stem cells through the TGF- $\beta /$ periostin/PI3K/AKT pathway. Chem Biol Interact 2020;331:109275. DOI PubMed

72. Wang T, Wang D, Zhang L, et al. The TGFß-miR-499a-SHKBP1 pathway induces resistance to EGFR inhibitors in osteosarcoma cancer stem cell-like cells. J Exp Clin Cancer Res 2019;38:226. DOI PubMed PMC 
73. Maurizi G, Verma N, Gadi A, Mansukhani A, Basilico C. Sox2 is required for tumor development and cancer cell proliferation in osteosarcoma. Oncogene 2018;37:4626-32. DOI PubMed PMC

74. Chen Y, Wang T, Huang M, et al. MAFB promotes cancer stemness and tumorigenesis in osteosarcoma through a Sox9-mediated positive feedback loop. Cancer Res 2020;80:2472-83. DOI PubMed

75. Subramaniam D, Angulo P, Ponnurangam S, et al. Suppressing STAT5 signaling affects osteosarcoma growth and stemness. Cell Death Dis 2020;11:149. DOI PubMed PMC

76. Fan H, Liu G, Zhao C, Li X, Yang X. Transcription factor Oct4 promotes osteosarcoma by regulating lncRNA AK055347. Oncol Lett 2017;13:396-402. DOI PubMed PMC

77. Xi X, Wu Q, Bao Y, et al. Overexpression of TBL1XR1 confers tumorigenic capability and promotes recurrence of osteosarcoma. Eur J Pharmacol 2019;844:259-67. DOI PubMed

78. Chen X, Zhang Q, Dang X, et al. Targeting the CtBP1-FOXM1 transcriptional complex with small molecules to overcome MDR1mediated chemoresistance in osteosarcoma cancer stem cells. J Cancer 2021;12:482-97. DOI PubMed PMC

79. Fan GT, Ling ZH, He ZW, Wu SJ, Zhou GX. Suppressing CHD1L reduces the proliferation and chemoresistance in osteosarcoma. Biochem Biophys Res Commun 2021;554:214-21. DOI PubMed

80. Gan Z, Han K, Lin S, Hu H, Shen Z, Min D. Knockdown of ubiquitin-specific peptidase 39 inhibited the growth of osteosarcoma cells and induced apoptosis in vitro. Biol Res 2017;50:15. DOI PubMed PMC

81. Xu W, Chen C, Xu R, et al. Knockdown of HuR represses osteosarcoma cells migration, invasion and stemness through inhibition of YAP activation and increases susceptibility to chemotherapeutic agents. Biomed Pharmacother 2018;102:587-93. DOI PubMed

82. Li S, Bai H, Chen X, et al. Soft substrate promotes osteosarcoma cell self-renewal, differentiation, and drug resistance through miR29b and its target protein spin 1. ACS Biomater Sci Eng 2020;6:5588-98. DOI PubMed

83. Zou Y, Huang Y, Yang J, Wu J, Luo C. miR-34a is downregulated in human osteosarcoma stem-like cells and promotes invasion, tumorigenic ability and self-renewal capacity. Mol Med Rep 2017;15:1631-7. DOI PubMed PMC

84. Liang X, Xu C, Wang W, Li X. The DNMT1/miR-34a axis is involved in the stemness of human osteosarcoma cells and derived stem-like cells. Stem Cells Int 2019;2019:7028901. DOI PubMed PMC

85. Liang X, Xu C, Cao X, Wang W. Isovitexin suppresses cancer stemness property and induces apoptosis of osteosarcoma cells by disruption of the DNMT1/miR-34a/Bcl-2 axis. Cancer Manag Res 2019;11:8923-36. DOI PubMed PMC

86. Yao J, Lin J, He L, Huang J, Liu Q. TNF- $\alpha /$ miR-155 axis induces the transformation of osteosarcoma cancer stem cells independent of TP53INP1. Gene 2020;726:144224. DOI PubMed

87. Guo X, Yu L, Zhang Z, Dai G, Gao T, Guo W. miR-335 negatively regulates osteosarcoma stem cell-like properties by targeting POU5F1. Cancer Cell Int 2017;17:29. DOI PubMed PMC

88. Zhang L, Yang P, Liu Q, et al. KLF8 promotes cancer stem cell-like phenotypes in osteosarcoma through miR-429-SOX2 signaling. Neoplasma 2020;67:519-27. DOI PubMed

89. Lavaud M, Georges S, Ory B. MircoRNA implication in therapeutic resistance and metastatic dissemination of bone-associated tumors. In: Heymann D, editor. Bone cancer: bone sarcomas and bone metastases - from bench to bedside. Academic Press; 2022. p. 447-56. DOI

90. Qu Y, Zheng S, Kang M, et al. Knockdown of long non-coding RNA HOXD-AS1 inhibits the progression of osteosarcoma. Biomed Pharmacother 2018;98:899-906. DOI PubMed

91. Lu B, He Y, He J, et al. Epigenetic profiling identifies LIF as a super-enhancer-controlled regulator of stem cell-like properties in osteosarcoma. Mol Cancer Res 2020;18:57-67. DOI PubMed

92. Yan GN, Tang XF, Zhang XC, et al. TSSC3 represses self-renewal of osteosarcoma stem cells and Nanog expression by inhibiting the Src/Akt pathway. Oncotarget 2017;8:85628-41. DOI PubMed PMC

93. He J, Ling L, Liu Z, et al. Functional interplay between long non-coding RNAs and the Wnt signaling cascade in osteosarcoma. Cancer Cell Int 2021;21:313. DOI PubMed PMC

94. Camuzard O, Trojani MC, Santucci-Darmanin S, et al. Autophagy in osteosarcoma cancer stem cells is critical process which can be targeted by the antipsychotic drug thioridazine. Cancers (Basel) 2020;12:3675. DOI PubMed PMC

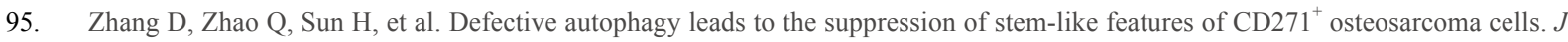
Biomed Sci 2016;23:82. DOI PubMed PMC

96. Wang JH, Gong C, Guo FJ, et al. Knockdown of STIP1 inhibits the invasion of CD133-positive cancer stem-like cells of the osteosarcoma MG63 cell line via the PI3K/Akt and ERK1/2 pathways. Int J Mol Med 2020;46:2251-9. DOI PubMed

97. Shu X, Liu H, Zhen R, et al. Hsp90 inhibitor 17-AAG inhibits stem cell-like properties and chemoresistance in osteosarcoma cells via the Hedgehog signaling pathway. Oncol Rep 2020;44:313-24. DOI PubMed

98. Hua Y, Jia X, Sun M, et al. Plasma membrane proteomic analysis of human osteosarcoma and osteoblastic cells: revealing NDRG1 as a marker for osteosarcoma. Tumour Biol 2011;32:1013-21. DOI PubMed

99. Chano T, Kita H, Avnet S, Lemma S, Baldini N. Prominent role of RAB39A-RXRB axis in cancer development and stemness. Oncotarget 2018;9:9852-66. DOI PubMed PMC

100. Takahashi N, Nobusue H, Shimizu T, et al. ROCK inhibition induces terminal adipocyte differentiation and suppresses tumorigenesis in chemoresistant osteosarcoma cells. Cancer Res 2019;79:3088-99. DOI PubMed

101. Liu F, Li L, Li Y, et al. Overexpression of SENP1 reduces the stemness capacity of osteosarcoma stem cells and increases their sensitivity to HSVtk/GCV. Int J Oncol 2018. DOI PubMed PMC

102. Tang ML, Bai XJ, Li Y, Dai XJ, Yang F. MMP-1 Over-expression promotes malignancy and stem-like properties of human osteosarcoma MG-63 cells in vitro. Curr Med Sci 2018;38:809-17. DOI PubMed 
103. Zhao T, Meng Y, Wang Y, Wang W. NDRG1 regulates osteosarcoma cells via mediating the mitochondrial function and CSCs differentiation. J Orthop Surg Res 2021;16:364. DOI PubMed PMC

104. Feng J, Lan R, Cai G, Lin J. TREX1 suppression imparts cancer-stem-cell-like characteristics to CD133- osteosarcoma cells through the activation of E2F4 signaling. Int J Clin Exp Pathol 2019;12:1134-53. PubMed PMC

105. Martins-Neves SR, Paiva-Oliveira DI, Fontes-Ribeiro C, Bovée JVMG, Cleton-Jansen AM, Gomes CMF. IWR-1, a tankyrase inhibitor, attenuates Wnt/ $\beta$-catenin signaling in cancer stem-like cells and inhibits in vivo the growth of a subcutaneous human osteosarcoma xenograft. Cancer Lett 2018;414:1-15. DOI PubMed

106. Nomura M, Rainusso N, Lee YC, et al. Tegavivint and the $\beta$-catenin/ALDH axis in chemotherapy-resistant and metastatic osteosarcoma. J Natl Cancer Inst 2019;111:1216-27. DOI PubMed PMC

107. Liu W, Zhao Z, Wang Y, et al. Dioscin inhibits stem-cell-like properties and tumor growth of osteosarcoma through Akt/GSK3/ $/$ catenin signaling pathway. Cell Death Dis 2018;9:343. DOI PubMed PMC

108. Wei D, Zhu X, Li S, et al. Tideglusib suppresses stem-cell-like features and progression of osteosarcoma by inhibiting GSK-3 $\beta$ /NOTCH1 signaling. Biochem Biophys Res Commun 2021;554:206-13. DOI PubMed

109. Wang $\mathrm{H}$, Zhang $\mathrm{C}, \mathrm{Xu} \mathrm{L}$, et al. Bufalin suppresses hepatocellular carcinoma invasion and metastasis by targeting HIF-1 $\alpha$ via the PI3K/AKT/mTOR pathway. Oncotarget 2016;7:20193-208. DOI PubMed PMC

110. Xiong Q, Wang X, Wang L, et al. BMP-2 inhibits lung metastasis of osteosarcoma: an early investigation using an orthotopic model. Onco Targets Ther 2018;11:7543-53. DOI PubMed PMC

111. Wang S, Hu H, Zhong B, et al. Bruceine D inhibits tumor growth and stem cell-like traits of osteosarcoma through inhibition of STAT3 signaling pathway. Cancer Med 2019;8:7345-58. DOI PubMed PMC

112. Gonçalves JM, Silva CAB, Rivero ERC, Cordeiro MMR. Inhibition of cancer stem cells promoted by Pimozide. Clin Exp Pharmacol Physiol 2019;46:116-25. DOI PubMed

113. Lillo Osuna MA, Garcia-Lopez J, El Ayachi I, et al. Activation of estrogen receptor alpha by decitabine inhibits osteosarcoma growth and metastasis. Cancer Res 2019;79:1054-68. DOI PubMed PMC

114. Hirozane T, Masuda M, Sugano T, et al. Direct conversion of osteosarcoma to adipocytes by targeting TNIK. JCI Insight 2021;6:137245. DOI PubMed PMC

115. Qu H, Xue Y, Lian W, et al. Melatonin inhibits osteosarcoma stem cells by suppressing SOX9-mediated signaling. Life Sci 2018;207:253-64. DOI PubMed

116. Li Y, Xian M, Yang B, Ying M, He Q. Inhibition of KLF4 by statins reverses Adriamycin-induced metastasis and cancer stemness in osteosarcoma cells. Stem Cell Reports 2017;8:1617-29. DOI PubMed PMC

117. Deguchi T, Hosoya K, Kim S, et al. Metformin preferentially enhances the radio-sensitivity of cancer stem-like cells with highly mitochondrial respiration ability in HMPOS. Mol Ther Oncolytics 2021;22:143-51. DOI PubMed PMC

118. Shang D, Wu J, Guo L, Xu Y, Liu L, Lu J. Metformin increases sensitivity of osteosarcoma stem cells to cisplatin by inhibiting expression of PKM2. Int J Oncol 2017;50:1848-56. DOI PubMed

119. Zhao B, Luo J, Wang Y, et al. Metformin suppresses self-renewal ability and tumorigenicity of osteosarcoma stem cells via reactive oxygen species-mediated apoptosis and autophagy. Oxid Med Cell Longev 2019;2019:9290728. DOI PubMed PMC

120. Paiva-Oliveira DI, Martins-Neves SR, Abrunhosa AJ, Fontes-Ribeiro C, Gomes CMF. Therapeutic potential of the metabolic modulator Metformin on osteosarcoma cancer stem-like cells. Cancer Chemother Pharmacol 2018;81:49-63. DOI PubMed

121. Koh H, Sun HN, Xing Z, et al. Wogonin influences osteosarcoma stem cell stemness through ROS-dependent signaling. In Vivo 2020;34:1077-84. DOI PubMed PMC

122. Ba G, Hua Z, Xu N, et al. Novel agent DMAMCL suppresses osteosarcoma growth and decreases the stemness of osteosarcoma stem cell. Cell Cycle 2020;19:1530-44. DOI PubMed PMC

123. Dai G, Deng S, Guo W, et al. Notch pathway inhibition using DAPT, a $\gamma$-secretase inhibitor (GSI), enhances the antitumor effect of cisplatin in resistant osteosarcoma. Mol Carcinog 2019;58:3-18. DOI PubMed

124. Oka N, Komuro A, Amano H, et al. Ascorbate sensitizes human osteosarcoma cells to the cytostatic effects of cisplatin. Pharmacol Res Perspect 2020;8:e00632. DOI PubMed PMC

125. Guo W, Wei B, Cheng T, Xu X, Ruan F, Xiang M. The Na+/K+ ATPase inhibitor ouabain attenuates stemness and chemoresistance of osteosarcoma cells. Med Sci Monit 2019;25:9426-34. DOI PubMed PMC

126. Gurunathan S, Jeyaraj M, Kang MH, Kim JH. Tangeretin-assisted platinum nanoparticles enhance the apoptotic properties of doxorubicin: combination therapy for osteosarcoma treatment. Nanomaterials (Basel) 2019;9:1089. DOI PubMed PMC

127. Ferreira de Oliveira JMP, Pacheco AR, Coutinho L, et al. Combination of etoposide and fisetin results in anti-cancer efficiency against osteosarcoma cell models. Arch Toxicol 2018;92:1205-14. DOI PubMed

128. Heymann MF, Schiavone K, Heymann D. Bone sarcomas in the immunotherapy era. Br J Pharmacol 2021;178:1955-72. DOI PubMed

129. Mesiano G, Grignani G, Fiorino E, et al. Cytokine Induced Killer cells are effective against sarcoma cancer stem cells spared by chemotherapy and target therapy. Oncoimmunology 2018;7:e1465161. DOI PubMed PMC

130. Wang W, Chen D, Zhu K. SOX2OT variant 7 contributes to the synergistic interaction between EGCG and Doxorubicin to kill osteosarcoma via autophagy and stemness inhibition. J Exp Clin Cancer Res 2018;37:37. DOI PubMed PMC

131. Lu SL, Wang YH, Liu GF, et al. Graphene oxide nanoparticle-loaded ginsenoside Rg3 improves photodynamic therapy in inhibiting malignant progression and stemness of osteosarcoma. Front Mol Biosci 2021;8:663089. DOI PubMed PMC

132. Tian J, Gu Y, Li Y, Liu T. CD271 antibody-functionalized HGNs for targeted photothermal therapy of osteosarcoma stem cells. Nanotechnology 2020;31:305707. DOI PubMed 
133. Mineo PG, Foti C, Vento F, et al. Salinomycin-loaded PLA nanoparticles: drug quantification by GPC and wave voltammetry and biological studies on osteosarcoma cancer stem cells. Anal Bioanal Chem 2020;412:4681-90. DOI PubMed

134. Gui K, Zhang X, Chen F, et al. Lipid-polymer nanoparticles with CD133 aptamers for targeted delivery of all-trans retinoic acid to osteosarcoma initiating cells. Biomed Pharmacother 2019;111:751-64. DOI PubMed

135. Chen F, Zeng Y, Qi X, et al. Targeted salinomycin delivery with EGFR and CD133 aptamers based dual-ligand lipid-polymer nanoparticles to both osteosarcoma cells and cancer stem cells. Nanomedicine 2018;14:2115-27. DOI PubMed

136. Gambera S, Abarrategi A, González-Camacho F, et al. Clonal dynamics in osteosarcoma defined by RGB marking. Nat Commun 2018;9:3994. DOI PubMed PMC

137. Tellez-Gabriel M, Cochonneau D, Cadé M, Jubellin C, Heymann MF, Heymann D. Circulating tumor cell-derived pre-clinical models for personalized medicine. Cancers (Basel) 2018;11:19. DOI PubMed PMC

138. Zhang W, Zhao JM, Lin J, et al. Adaptive fibrogenic reprogramming of osteosarcoma stem cells promotes metastatic growth. Cell Rep 2018;24:1266-77.e5. DOI PubMed

139. Heymann MF, Lézot F, Heymann D. The contribution of immune infiltrates and the local microenvironment in the pathogenesis of osteosarcoma. Cell Immunol 2019;343:103711. DOI PubMed

140. Avnet S, Lemma S, Cortini M, et al. The release of inflammatory mediators from acid-stimulated mesenchymal stromal cells favours tumour invasiveness and metastasis in osteosarcoma. Cancers (Basel) 2021;13:5855. DOI PubMed PMC

141. Avnet S, Lemma S, Cortini M, Di Pompo G, Perut F, Baldini N. Pre-clinical models for studying the interaction between mesenchymal stromal cells and cancer cells and the induction of stemness. Front Oncol 2019;9:305. DOI PubMed PMC

142. Bonuccelli G, Avnet S, Grisendi G, et al. Role of mesenchymal stem cells in osteosarcoma and metabolic reprogramming of tumor cells. Oncotarget 2014;5:7575-88. DOI PubMed PMC

143. Baglio SR, Lagerweij T, Pérez-Lanzón M, et al. Blocking tumour-educated MSC paracrine activity halts osteosarcoma progression. Clin Cancer Res 2017;23:3721-33. DOI 